\title{
Effect Of Hyperlipidemia On Nerve Conduction Velocity In Type II Diabetes Mellitus
}

\author{
Dr.Nidhi Yadav, Dr. Anjali N. Shete, Dr. S.T.Khan \\ ${ }^{I}$ Senior Resident, Department Of Physiology Government Medical College, Aurangabad . \\ ${ }^{2}$ Associate Professor, Department Of Physiology Government Medical College, Aurangabad. \\ ${ }^{3}$ HOD And Professor, Department Of Physiology Government Medical College, Aurangabad
}

\begin{abstract}
:
Objectives: The pathogenesis of neuropathy in type II Diabetes Mellitus is multifactorial. Hyperlipidemia may contribute to the development of diabetic neuropathy. This study aimed to assess the correlation between hyperlipidemia and diabetic neuropathy.

Material And Method: The study included 60 known cases of Type II diabetes mellitus attending diabetic OPD at GMCH, Aurangabad of age 30-60 years with duration of 5-10 years. The cases were divided into two groups; Group I included diabetic patients with normolipidemia and Group II included diabetic patients with hyperlipidemia. Biochemical investigations included HbAlc, total cholesterol and triglycerides. Nerve conduction velocity was done by computerized Micromed RMSEMG system.Statistical analysis was done by unpaired student's $t$ test.
\end{abstract}

Results: The study revealed significant reduction in conduction velocity in diabetic patients with hyperlipidemia.

Key Words: Diabetes Mellitus Hyperlipidemia Nerve Conduction Velocity

\section{Introduction}

Diabetic neuropathy is the most common neuropathy and is associated with a wide range of clinical manifestations. It tends to occur after 50 years of age, and mostly in patients with long standing diabetes mellitus. (1) It results from micro vascular injury involving small blood vessels that supply nerves. But, macro vascular pathogenesis is also involved.(2) The pathogenesis of sensori motor neuropathy in Type II diabetes mellitus is multi factorial and related metabolic disturbances such as hyperglycaemia, hyperlipidemia, oxidative and nitrosative stress all contribute to the development of this complication.(3)

Hyperlipidemia is a common metabolic problem characterized by abnormal lipid metabolism in which one of the major plasma lipids-cholesterol and triglycerides are elevated.(4) Dyslipidemia is a significant contributor to the development of diabetic neuropathy via inducing oxidative stress in root ganglia sensory neurons. $(5,6)$ The incidence and the prevalence of hyperlipidemia has recently increased.

Keeping all this in mind, our study was aimed to explore the correlation between hyperlipidemia and diabetic neuropathy.

\section{Material And Method}

The study was conducted in the department of Physiology, Government medical college and hospital, Aurangabad. A total number of 60 patients with a history of diabetes since 5-10 years attending the diabetic OPD were selected. They were of 30-60 years of age. They were grouped into two groups of 30 each. Group I included 30 diabetic patients with normo lipidemia and Group II included 30 diabetic patients with hyper lipidemia. No one had any medical condition to be associated with polyneuropathy, unusual dietary habits, family $\mathrm{H} / \mathrm{O}$ peripheral nerve disease and consumed alcohol or drugs with potential neurotoxic effects. No one received any lipid lowering agents before the electrophysiological examination. They were carefully examined for any neurological or autonomic dysfunction. A consent was obtained from each participant. A venous blood was collected for biochemical investigations which included $\mathrm{HbAlc}$, total cholesterol and triglycerides. Computerised Micromed RMSEMG system was used for electrophysiological analyses using surface electrodes. Nerve conductions velocities of sural nerve ( sensory) and posterior tibial nerve ( motor) were recorded. 


\section{Statistical Analysis}

The results were analyzed using Microsoft Excel 2007. The data was analyzed and compared by using unpaired Student's $t$ test. The values were expressed as mean \pm S.D.The $P$ value $\leq 0.001$ was considered as significant.

\section{Results}

The HbAlc level in Group I was $7.053 \pm 0.43$ and in Group II ; it was $7.04 \pm 0.45$. The total cholesterol was $183.4 \pm 9.25$ in Group I and $207.2 \pm 11.02$ in Group II. The triglycerides in Group I was $135.26 \pm 4.67$ and in Group II was $147.36 \pm 10.15$. The lipid profile showed a statistically significant change. Refer to Table 1.

The significant changes were observed in terms of decreased conduction velocity of both sural nerve and posterior tibial nerve. Refer to Table 2. The NCV of sural nerve in Group I was $41.68 \pm 1.29$ and of posterior tibial nerve was $39.93 \pm 1.55$. The conduction velocity in Group II of sural nerve was $46.34 \pm 0.88$ and of posterior tibial nerve was $44.57 \pm 0.96$. the study showed both sensory and motor neuropathy in diabetic patients which was more pronounced in hyperlipidemic subjects as compared to normolipidemia.

\section{Discussion}

The results observed in the study clearly demonstrate the existence of disturbances in lipid metabolism in Type II diabetes mellitus patients with peripheral neuropathy. This observation is in agreement with Shera et al (1) who reported significant high ratios of atherogenesis in diabetic patients. Neuropathy in Type II DM co-exists with metabolic lipid disturbances was also shown by Fakir S. et al (7). The NCV revealed a significant decrease of both sensory and motor nerves. The findings are commonly observed in clinical practice in diabetic patients. It is important to mention that use of multivitamins may alter the NCV study. The previous studies showed that vitamins may reverse the symptoms and pathophysiology of diabetic neuropathy (8). Patients on oral hypoglycemic agents may develop Vit B12 deficiency and VitB12 is effective in alleviating the symptoms of neuropathy (9).

The lipid pattern in this study were similar to that observed by Fakhir et al (7), Abdul Ghani (10) which showed a significant association of metabolic syndrome in Type II DM with a high risk of neuropathy. However, Agarwal et al found that neuropathy did not have any significant correlation with lipid profile abnormalities in Type II DM patients (11).

The underlying mechanism of the neuropathy is mixed axonal degeneration and segmental demyelination(12). The segmental demyelination is thought to be due to the axonal degeneration(13). The duration of the disease process might affect the results because the turnover of lipids in myelin is slow. The turnover of the lipids in the outer layers of the myelin sheath is considered to be rapid than in the inner layers. There is a great possibility that serum lipid abnormality have a direct effect on cell membrane and might influence the structure of myelin sheath (14). The abnormal function of nerve may be due to the abnormal actions of lipoproteins as enzyme cofactors and as bound intermediate in the biosynthesis of polysaccharide and proteins or abnormal serum lipids could mediate nerve infarction via fat embolism or lipid induced platelet aggregation(15).

\section{Conclusion}

We conclude that there is definite association in metabolic lipid disturbances with neuropathy in Type II DM . It is more pronounced in cases of poor glycemic control.

\section{Key Message}

The study reinforced an important message to clinicians to assess lipid profile and evaluate for preclinical atheroscelerosis in diabetic patients with neuropathic signs and symptoms.

\section{Limitations}

Lipid ratios were not included in our study and $\mathrm{F}$ wave study was also not done. Both of these parameters definitely should have given some additional information.

\section{References:}

[1]. Shera A.S., Jawad F ., Maqsood A, Jamal S, Azfar M, Ahmed U, Prevalence of chronic complications and associated factors in type II diabetes, J.Pak Med. Assoc. 2004;54: 54-59

[2]. Tesfaye S, Boulton AJ, Dyck P J, Freeman R, Horowitz M, Kempler P, et al. Diabetic neuropathies: update on definitions, diagnostic criteria, estimation of severity and treatments. Diabetes care. 2010;33:2285-2293

[3]. Vinik A.The approach to the management of the patient with neuropathic pain. J.Clin.Endocrinol Metab.2010; 95: 4802-4811.

[4]. Smith G.D., Ebrahim S. Is it time to call it a day. Int.J.of Epidemiology. 2001; 30(1):1-11 
[5]. Vincent AM, Hinder LM, Pop-BusuiR,Feldman EL. Hyperlipidemia: A new therapeutic target for diabetic neuropathy. J Peripher Nerv Syst.2009; 14: 257-267

[6]. Vincent AM, Hayes JM, Mclean LL, Vivekanandan-Giri A, Pennathur S,Feldman EL. Dyslipidemia induced neuropathy in mice: The role of oxLDL/LOX-1, Diabetes. 2009:58: 2376-- 2385.

[7]. Fakhir S, Al-Ani, Marwan S. Al-Nimer and Fatima S Ali. Dyslipidemia as a contributory factor in etipathogenesis of diabetic neuropathy: 2011: 15(2); 110-114

[8]. Walker MJ,Morris LM, Cheng D. Improvement of cutaneous sensitivity in diabetic peripheral neuropathy with combination Lmethylfolate, methylcobalamin, and pyridoxil 5'-phosphate. Rev Neurol Dis. 2010: 7: 132-139

[9]. Talaei A, Siavash M, Majidi H, Chehrei A. Vitamin B12 may be more effective than nortryptiline in painful diabetic neuropathy. Int J Food Sci Nutr. 2009: 60: 71-76.

[10]. Abdul-Ghani M, Nawaf G, Nawaf F, Itzhak B, Minuchin O, Vardi P. Increased prevalence of microvascular complications in type 2 diabetes patients with the metabolic syndrome. Isr.Med Assoc J . 2006; 8: 378-382.

[11]. Agrawal RP, Sharma P, Pal M, Kochar A, Kochar DK. Magnitude of dyslipidemia and it's association with micro and macro vascular complications in type 2 diabetes; A hospital based study from Bikaner. Diabetes Res Clin Pract. 2006; 73: 211-214

[12]. Seley R, stephens T, Tate P. Essential of Anatomy and Physiology $4^{\text {th }}$ edition 2002; Mcgraw Hill company, Boston: $355-376$.

[13]. Kassem HS, Azar ST, Zantout MS, et al . Hyperlipidemia and peripheral neuropathy in Neurologically asymptomatic patients Neuroendocrinol. Lett,2005; 26(6): 775-779.

[14]. Vincent AD, Robert C, Sergott T, et al. Ischemic optic neuropathy as the first manifestation of elevated Serum cholesterol level. Opthal 2003; 54(7): 478-490.

[15]. Aravindan PD, Lioyed M, Scalp pain and Hyperlipidemia, Int. J. Lin. Pract 2000; 54(7): 478-490.

Table No 1 : Lipid Profile In Group I And Group II

\begin{tabular}{|c|c|c|}
\hline PARAMETERS & GROUP I & GROUP II \\
\hline HBA1c $(\%)$ & $7.053 \pm 0.43$ & $7.04 \pm 0.45$ \\
\hline TC $(\mathrm{mg} / \mathrm{dl})$ & $183.4 \pm 9.25$ & $207.2 \pm 11.02 * *$ \\
\hline TG $(\mathrm{mg} / \mathrm{dl})$ & $135.26 \pm 4.67$ & $147.36 \pm 10.35 * *$ \\
\hline TC $=$ total cholesterol & $\mathrm{TG}=$ triglycerides & $* *=$ highly significant
\end{tabular}

Table No 2 : Nerve Conduction Velocity In Group I And Group II

\begin{tabular}{|l|l|l|}
\hline NCV $(\mathrm{m} / \mathrm{s})$ & GROUP I & GROUP II \\
\hline SURAL NERVE & $41.68 \pm 1.29$ & $39.93 \pm 1.55 * *$ \\
\hline POSTERIOR TIBIAL NERVE & $46.34 \pm 0.88$ & $44.57 \pm 0.96 * *$ \\
\hline
\end{tabular}

$$
\mathrm{NCV}=\text { nerve conduction velocity } \quad * *=\text { highly significant }
$$
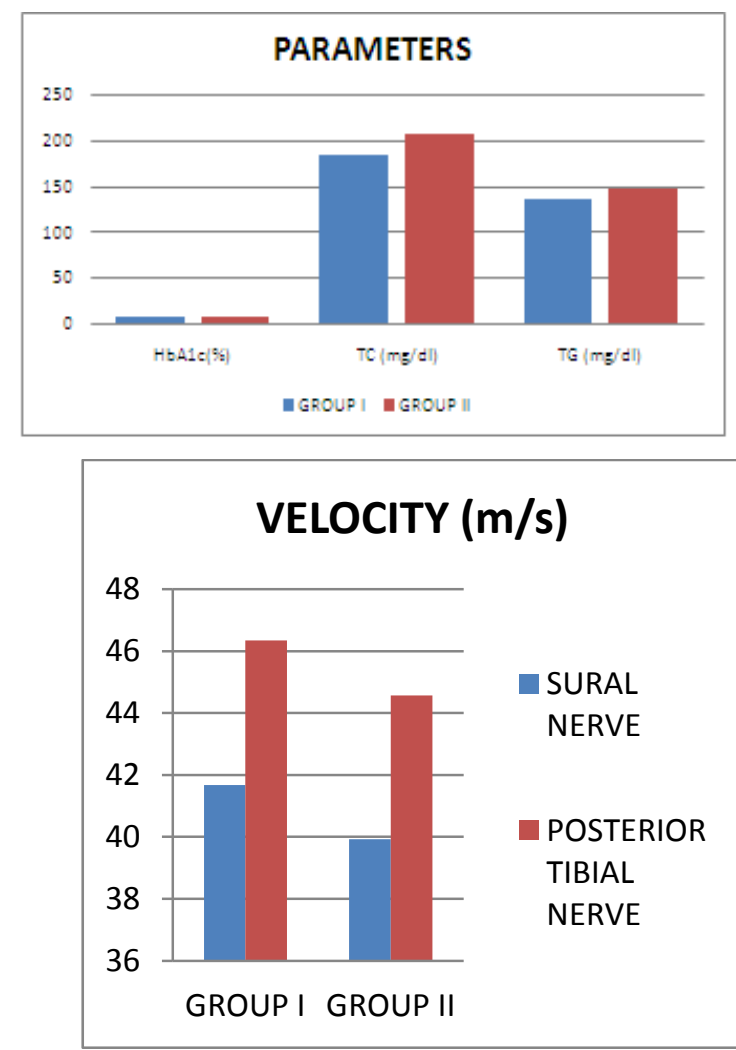